\title{
On the Translation of Ceramic Culture-Loaded Words from the Eco-translatology Perspective
}

\author{
$\mathrm{Na} \mathrm{Hu}{ }^{1, a^{*}}$, Hui Wang ${ }^{1}$ and Xing $\mathrm{Xu}^{2}$ \\ ${ }^{1}$ School of Foreign, Jingdezhen Ceramic Institute, Jingdezhen 333403, China \\ ${ }^{2}$ School of Information, Jingdezhen Ceramic Institute, Jingdezhen 333403, China \\ anala_whu@aliyun.com
}

Keywords: Culture-loaded words; Ceramic culture; Eco-translatology; Translation

\begin{abstract}
Culture-loaded words are culture-specific, and the C-E translation should carry and reflect the culture meanings. Constrained by the culture of source language, the translation activity promotes its development by absorbing new cultural factors from the target language, hence the heritage and development of ceramic culture is based on the cultural communications. Translation, as the bridge of communication and culture, its results not only enriches the distinctiveness of regional ceramic culture but also gives the translators a dynamic ecological environment. As the main body of translation, translators should have a good command of the culture of source language and a capability in choosing the ecological environment of translation as well as its final translation writing. This paper stresses that, based on eco-translatology principle, the translation activities and results are bound to nourish cultural exchanges and development.
\end{abstract}

\section{Introduction}

The ecological environment of translation, which restricts the translators to a certain scope of adaptation and optimization options, refers to the social and cultural environment combined by source language, original text and target language. Eco-translatology, which takes translation as part of the adaptation and selection process across cultures, focusing on the integrity of translational ecosystems and the central role of the translators, is first proposed by Hu Lengthen of the Macao Polytechnic Institute.

The social and cultural environment, which is abbreviated as socio-cultural environment, can be illustrated by customs, lifestyles and values that characterize a society or group. The present social-cultural ceramic environment, which can be embodied by the shared value that the development for ceramic industry is "heritage--innovation--open--fusion", therefore constitutes the ecological environment for translation associated with ceramics. In the translation activities associated with ceramics, on the one hand, the translators are constrained by the social-cultural environment because they have to adapt to the background culture; on the other hand, the translators could consequently bring influence on ceramic culture by selecting words from source language and manipulating the text for target language. Taking the translation of culture-loaded words as a specific example, this paper probes into how the translators comprehend, adapt, select and then translate during the translating process. Only by "adequate, appropriate and moderate" translation, could the translators extend the "true, good and beautiful" aspects of ceramics to the readers, and create a "diversity could be complementary" cultural environment, and consequently promote the communication and development of different cultures.

\section{The Cultural Translation of Ceramics}

The Ceramic Culture-loaded Words. "Culturally-loaded words and expressions are loaded with specific national cultural information and indicate deep national culture. They are the direct and indirect reflection of national culture in the structure of words and expressions" (Hu 2003). Culturally-loaded words can be seen as word, idioms, or expressions which have a typical meaning in a particular culture. Culture-loaded words are words that embedded in their distinctive culture and foreigners need to 
understand their cultural implications. For example, it's easier for foreigners to figure out what is a Longboat ('lucky money' wrapped in red envelops), but it's confusing for them to understand the two-children-one-family policy without knowing about the history of Chinese family policy.

Similarly, in the real practice of C-E translation, there are a set of unique words which loaded a lot of cultural information. Attributing to the distinctive regional ceramic industry, some words "are particularly tied to the way of life and its manifestations that are peculiar to a community that uses a particular language as its means of expression" (Newark 1998), and there are no identical words in the English language. The payment for potters could be a case in point; their wages could be paid in "Zhisi meat", "Moli wine", or "chief master dismissal tee", because in the local, after paying the money, the employers could invite their potters to feast to show their respect. Anyhow, all those jargon, which are culturally-sensitive and "may convey a concept utterly new for the target"(Mona Baker 2000), distinctively exit in the local ceramic industry. In addition, some words and idioms may appear to be simple and easy to find a identical expression in the target language, but the connotation maybe extended or diminished. A porcelain engraving arts-craft was translated as "Going back home", Pro. Li (2005) noted that the cultural information of "a newly-wed bride should visit home" has been diminished; the better interpretation could be "A married woman visits her maiden home". Therefore, the translations of culture-loaded words are cultural specific. All those custom terms, jargon and slang, which are part of the ceramic culture for thousands of years, are defined as Ceramic Culture Loaded Words.

The Importance of Translation. Whether it is as an activity itself, as a process of activity, or as a result of the activity, translation has a certain cultural meaning and connotation. Ceramic culture is rooted in the local culture, in ceramic craft and ceramic art to be specific, and the C-E translation of a term, a jargon or an arts-craft first of all should take the cultural factors of source language into consideration, and then fully interpret the artist's cultural conception of his work. The artist talks to the audience via his arts-work; the translator "learns a foreign language usually for the purpose of acquiring the communicative ability across cultures" (Hu, 2003), and his task is not simply to switch from the two different language but to make the communication between the artist and the audience understood and achieved. However, In terms of ceramic culture, the embodiment of the ceramic art, regardless of art form or oral language, could be dramatically different in different cultures. A western artist could use a sculpture of a little girl with a poppy to show "innocence", while in one of Prof. Yu's porcelain plastic series (2016) named "Innocence", there is a lying boy on the ground with his pants open-baked and his bottoms shown. How could the translator explain that this the traditional rather than improper dressing for toddlers in his translation? Take the C-E translation of porcelain engraving craft "荷花仙子He Hua Xian $\mathrm{Zi"} \mathrm{for} \mathrm{example,} \mathrm{some} \mathrm{translators} \mathrm{swiftly} \mathrm{find} \mathrm{identical} \mathrm{words} \mathrm{of} \mathrm{"He} \mathrm{Hua"} \mathrm{and} \mathrm{"Xian} \mathrm{Zi"} \mathrm{in}$ English, and the translation turns out to be "Lotus and Fairy". The translation seems to be right and identical at first sight, however, in the Chinese culture, Lotus is the name of the fairy and the fairy is a household figure in folktales. Without knowing the exact meaning of the certain culture-loaded works, the translation task of "The Lotus Fairy" seems simple but impossible.

Shouldering the task of cross-cultural communication, the translators are confronted with the biggest difficulty, which is not on the language level but on the cultural differences, such as the translating of the ceramic culture-loaded words, the transliteration of ceramic exhibits, and the translation of ceramic works. Therefore, the translation of culture-loaded words should take comprehension of cultural connotation as first priority, and the translators are bound to totally understand the cultural artistic conception and cultural factors of certain words, works and customs. What in due course is the "adequate, appropriate and moderate" expression of his understanding in target language

\section{The Translation Principle and Practice}

The Translational Eco-environment. Hu (2003) initially tried to combine Ecology with Translation, aimed at watching the interactions between translators and the translation ecosystem from the ecological perspective. Since then, the research path of Eco-translatology has been widely understood and accepted. The keynote for this theory is "eco" and "adaption-selection". Translational eco-environment is defined as "the worlds of the source text and the source and target languages, comparing the linguistic, 
communicative, cultural and social aspect of translating, as well as the author, client, and reader"(Hu 2003). The relationship between translation and its environment is described as "interconnected and interacted state among the subjects of translation, as well as the interconnected and interacted state between the subjects and the outer environment" (Fang 2011). The outer environment is composed of the natural environment and the social environment, and this paper focuses on the social-cultural one which can also be classified into the objective and subjective environment. Eventually, translation can be regarded as a selection activity of the translators' adaption to fit the translational Eco-environment.

Culture factors have a significant binding force to translation activity, and vice versa, all the translation practice extraordinarily promotes the development of cultures involved. There is no doubt that the translation of ceramic works laid the foundation of cultural diffusion, and eventually the new factors absorbed during the translating process contribute to the development of ceramic culture. In the real practice associated with ceramic culture-loaded words, the translators consciously decide and implement how to comprehend and select the cultural factors, and then how to adapt himself to both the source and target language. The translators imitatively have to comprehend the artworks and the artists as a reader, and simultaneously have to interpret the social-cultural connotation as an author. Therefore, the translators accomplished the three stages of translating: having been selected by the translational eco-environment, adapting and selecting the cultural factors in source language and then selecting or deciding on the form of the final target language.

Comprehension---Adaption---Selection---Translation. The social-cultural factors only post part of the background environment for translators, and "A translator must engage in thousands of decisions involving bother selection and arrangement to fit another culture, a different language, diverse editors and publishers, and finally a reading audience" (Nida 2000). Since the ceramic culture-loaded words are most of the case culturally specific, the translation principle and method will be discussed with respect to culture and language. In the process of culture-loaded words' translating, the translators are compelled to both adapt and select and the relationship between the real translating process and the social-cultural environment can be illustrated by the three steps: preparing, translating and surviving of final text.

The artwork "喜上眉梢", which is one of the exhibits on JICF (Jingdezhen International Ceramic Fair), is an excellent interpretation of Chinese culture and ceramic works. The translators have to comprehend the meaning of the phrase and instinctively perceive that "喜" is the Chinese cultural elements; this is the adaption to the source text, and the comprehension and adaption constitute the preparing step. In the next step, the transistor could find many words to express the joyful mood in English, but he has to select one on the basis of his understanding of the source text and he will find that there is shared word "happiness". The Chinese name, either be named after a cultural factor, or a artistic conception, or a wish, has a cultural information that can be omitted to the Chinese while can obscure to the foreigners. "Shared" means that the translator has already adapted himself to the target language and decided on the final text. There are two versions of translation: "Happiness Appears on the Eyebrows" and "egg-green glazed vase with sculpted peach branch", the former one strives to keep the cultural information while the latter remains on the explanation of technology and process. Technically, both versions are correct, but the latter could not among the reading audience because of the loss of cultural information.

To sum up, the translation of culture-loaded words should start with the comprehension of the cultural connotation of source text, and then the translators could select words and expressions by adapting both to the source and target language, the final step could be the natural selection of final target text. The translators' adaption and selection eventually put the translation activity and process back into the "eco" environment, and the "survival of the fittest"(Han 2013) nourishes new cultural elements for the whole eco-environment.

Adequate. Appropriate and Moderate Expression. The key words of translational eco-environment are harmony, adaption-selection, natural selection and survival of the fittest translation. Then, what is the fittest translation of a certain translating practice? In this case, what is the best interpretation of a certain culture-loaded word? The fittest is not the rival between rights or wrong, it is 
about the fittest expression to interpret the source test and to fit the target text. The fittest isn't simply modified by "only", and the fittest expression could be adequate, appropriate and moderate.

Even though it refers to the same thing, the term or the artwork could have different versions of translation. For example, the Color-glazed Porcelain can be referred as sacrificial-red porcelain altar red, or $\mathrm{Ji}$ red in professional dictionaries. In the process of the unity of the translation, the translators happened to know about the folk tales, myth and legends implied in this porcelain, in other words, the unity select the fittest expression in the cultural environment. The JICF exhibit "washer decorated with a pair of fish in sacrificial red", which weighs a lot on the feature of glaze, is a good case in point. Therefore, the first principle of the fittest expression is to adequately keep the cultural information of source text.

According to Nida's translation criterion (2000), the translators should strive to find the maximum equivalency between the source and target text, but his equivalence refers to both formal correspondence and dynamic equivalence. The cultural information of culture-loaded words in source language could not find an identical/equivalent item in the target language, therefore, the translators need to adapt and select on the purpose of find the dynamic equivalence. For example, the translation of "一个 300 件的花瓶" could be translated as "300 pieces of vase", and it will cause a break-down communication. "Jian件" is a distinctive unit of measurement for ceramic trade, which refers to the size rather the number of vases, and there is no such measurement unit in English. The translators are compelled to adapt to this unique term, and add explanation in his expression. Therefore, the following principle of the fittest expression is to appropriately comprehend and interpret the culture-loaded words.

$\mathrm{Hu}$ also notices that "Undergoing the translating process, whether its adaption or selection, are all translator-centered---adaption means the translators' selective adaption and selection refers to the translators' adaptive selection" ( $\mathrm{Hu}$ 2003). The interacted relationship of adaption and selection is bounded to the last principle of the fittest expression that translators have to be closer to the target readers. The payment for potters could be a case in point; their wages could be paid in "Zhisi meat", "Moli wine", or "chief master dismissal tee". Zhisi is the embodiment of source cultural information, "meat" is easier for target readers to understand, and this "literal+liberal" way is combined with the translators' adaption and selection.

\section{Summary}

"Inheriting the traditional culture, fusing the international ceramic arts" is the due course for the heritage and development of local ceramic culture, and the translation of culture-loaded words functions as the bridge of cultural communication home and abroad. The C-E translation of culture-loaded words could constitute a great challenge for translators, but it is the right reflection of translational Eco-environment for ceramic culture-loaded words. As the subject of translation process and activity, only by adapting and selecting could the translators to fit in the target language. Based on a good command of cultural background, the translators should use various effective translating methods to create a "heritage--innovation--open--fusion" translational Eco-environment.

\section{Acknowledgments}

This paper was supported by the Science Foundation of Jiangxi Provincial Department of Education (GJJ14639,GJJ151547), Social sciences planning project of Jiangxi province(14yyq03),A Special Fund for Mid-aged and Yong Teachers as Visiting Scholars in Jiangxi General Undergraduate Universities.

\section{References}

[1] Fang Mengzi, On Translational Eco-environment, Shanghai Translation. (2011)

[2] Han Wei, Reinvestigation of "Translational Eco-environment" and "Survival of the Fittest", Foreign Language Research. (2013) 
[3] Hu Gengshu, Translation as Adaption and Selection, Perspectives: Studies in Translation, Qinghua University. (2003)

[4] Hu Gengshu, Eco-translatology: Construction and Interpretation, Hubei Education Press, 2004.

[5] $\mathrm{Hu} \mathrm{Na}$, On the Heritage and Development of Ceramic Culture from the Eco-translatology Perspective, Jingdezhen Comprehensive College Journal. (2016)

[6] Lin Yuewu, Yang Qin, An Investigation into the Culture-Loaded Words Learning by English Majors in a Vocational College in China, English Language Teaching. (2015)

[7] Mona Baker, In Other Words: A Course book on Translation, Oxford University Press, 2000.

[8] Newmark. P, More Paragraphs on Translation, Cleveton etc. Multilingual Matters, 1998.

[9] Nida. E. Princeples of Correspondence, In Laurence Venuti (ed.) the Translation Studies Reader. London, New York: Routledge, 2000. 